\title{
The Effect of Language Changes on Culture Cause by Producing Knowledge and Technology
}

\author{
Ali Mohammadi Bolbanabad ${ }^{1, a}$, Rouzbeh Hanifi ${ }^{2, b}$ \\ ${ }^{1}$ Department of Elementary Educational Sciences, Islamic Azad University, \\ Qorveh Branch, Qorveh, Iran \\ 2Department of English Language, Islamic Azad University, Qorveh Branch, Qorveh, Iran \\ ${ }^{a, b}$ E-mail address: Rahbord10@gmail.com, Roozbeh1241@gmail.com
}

\begin{abstract}
The Language is one of the instruments that changes by political and cultural evolutions (changes) and revolutionize during the humans history. But the main thing for the power and honor of each nation and government is protecting their culture and local language against these changes. The language evolution is inevitable. As the entrance of any other events is very common affair so the entrance of terms and any structure is common, too. The main language evolution reasons are because of the entrance of industrial and cultural phenomenon, political, economic and cultural relations, and arrival of those who educated abroad, geographical factors (having mutual border), taboos and military conflictions. These evolutions are semantic and not accidental and irregular. Systematic evolution is a part of language identity and maybe a part of human's identity. Changes in language is not always from extrinsic factor but also the language has a natural motion and it changes based on society needs. This evolution is too slow and gradual. But the main reason of entrance foreign terms that is one of the important factors of language changes is by improvement of technology in the world that producing scientific and technical instrument in such a high speed that is innumerable. As these instruments and tools enter other countries, they also enter their commercial names and known with these names. Sometimes in translation the scientific books, translators can't find suitable equivalents and synonymous because of the abundant numbers of the technical terms and lack of time, so they enter the original terms and use them in their translation.
\end{abstract}

Keywords: Culture; Technology; Language Evolution

\section{INTRODUCTION}

Language as technical, social, cultural instrument has a special role in achieving cultural knowledge; this social phenomenon also has a particular importance in socialization and acculturation. In other hand language can remake racial and cultural identity of a society during the evolution in the history and assist it as a distinction from animal system. In anthropology point of view, language act like a mediator that transmit culture knowledge from one generation to others; and this cultural technique instrument has an important effect on growth and mental cultural development of human being. In a simple expression, it's linkage between humans; and this connection in petty level includes symbolic and social actions, that transmit among different races of each society. Language is a result of social and 
cultural events that is one of the special phenomenons in humans social living and mesh like a sinew and seems inevitable phenomenon like sleep and food in our daily life. For realizing an importance of language it's just enough to think about the lack of it, then it can easily be understandable that human civilization and culture will destroy, "Language is an important and noticeable phenomenon that should be studied with different aspects." (Geranpaye, 1998). In recent years, the moral and cultural values changed in our society that was often against values that govern on society. These changes were so inevitable and visible that understanding its causes was opposed by experts of social and cultural science and even general people. It's remarkable that cultural evolution was in any society and it appeared in a form of acculturation, cultural publication and cultural evolution or even cultural invasion and camisade (Foroogh and Torabi, 2009).

One of the reasons of this evolution is changing in language, according to the traditional directors belief, original and pure language always belong to the old eras and any changes in its structure shows the chaos and disorderliness in that language and it ruins and collapses our ancestor's language. The main language changing reasons are because of the entrance of industrial and cultural phenomenons, political, economic and cultural relations arrival of those who educated abroad, geographical factors (having mutual border), taboos and military conflictions. These evolutions are systematic and not accidental and irregular. Systematic evolution is a part of language identity and maybe a part of human's identity. Changes in language is not always from extrinsic factor but also the language has a natural motion and it changes based on society needs. This evolution is too slow and gradual. But sudden invasion of foreign languages because of increasing the political power and their penetration in one side and keen changes of society needs, prompt the language evolution process during particular period of history. But the main reason of entrance foreign terms that is one of the important factors of language changes is by improvement of technology in the world that producing scientific and technical instrument in such a high speed that is innumerable. As these instruments and tools enter other countries, they also enter their commercial names and known with these names.

Sometimes in translation the scientific books, translators can't find suitable equivalents and synonymous because of the abundant numbers of the technical terms and lack of time, so they enter the original terms and use them in their translation, and according to this matter that language has a basic role in transmitting the cultural heritages, and the changed language is completely against and strange for the previous cultural heritages, and it can't have any role in transmission the cultural heritages, Therefore according to this matter, this article was purposefully done to determine the effects of language changes on cultural evolutions cause by producing knowledge and technology with special emphasize on Iran's society and also present solution.

\section{RESEARCH METHODOLOGY}

This article is a result of qualitative study that Beredy method is used in it. Beredy method includes for phases, description (Berry), interpretation (Pourtingas), adjoining (Dasen) and comparison (Kluckhohn). In description, research phenomenons notate based on witnesses and information and then with adequate supplies, they are prepared for surveying and criticism in next phase. In interpretation, the described information is analyzed and checked out. In adjoining phase, that information that is prepared in two previous phases, 
classify to make a frame for comparing the equalities and differences. In comparison phase, the research matter is survived and compared based on equalities and differences details.

\section{THEORETICAL FRAME}

\section{1. Culture}

There are different theories and sometimes contradictory definition about culture. Some of them describe culture as an acquisitive matter and emphasize on it, they define it in this way: "It's collection of patterns and moral norms that transmit from one generation to others by learning (Salibi, 2003, quotation from Razavi, 2013). Sometimes they define culture as thews of living (Tavasoli, 2007, quotation from Razavi). Mative Arnold is one the English literary thinkers that assist culture in its idealistic aspect and formation of values, and in his point of view, culture include: search for absolute perfection, using best thoughts and the sayings as matters that have the most relation and connection with us. Arnold introduces culture as a basic principle that controls all of society activities (Jonson, 1999, quotation from Razavi). Sociologists emphasize on Tyler's definition as the most complete definition, he said: culture includes of complex collection of sciences, knowledges, arts, thoughts and believes, provisions, customs, traditions and briefly every thoughts and habits that any human achieve as a member of society (Mohseni, 2006).

\section{2. Language}

Language is one of the greatest sources of socialization. In fact, this is not means that social communication disable in lack of language but means that a common speech act as a powerful social stability sign for those who speak a language (Niazi and Co-workers, 2013). Language was always considered as social phenomenon and this cause an improvement (growth) a branch of linguistics called "sociology of language". Sociologists believe that humans born in social world and learning process occur in communicating with others (Donato, 2000). In this attitude, learning new language is not restricted just by learning new language is not restricted just by learning grammar, vocabulary and phonetic system; but learning new language transform into trying for attending social communion and new culture. From this aspect, language is a recognition and social process, and we learn it by attempts (Paulo and Lantoloph, 2000).

\section{3. Cultural and Social Function of Language}

\subsection{Language and Culture}

As there are various definitions about culture, it's better to say our polestar definition at first so that we understand its relationship with language. Culture is a part of cognition that enter the people's common mentality or society or in universal people's living. The meaning of cognition it's not just refer to pictorial confirmation or mental awareness, but it's general definition that includes feeling, emotions, attitudes, believes and habits and traditions. Culture includes those kind of believes, knowledge, values, norms and habits and traditions that transmitting by teaching and training and show themselves in plural form. According to the Vorf and Sapir's viewpoint, language makes and forms the main core of the culture. Actually, language is fundamental instrument for understanding human behavior, and we can realize that how humans see, describe and interpret their environment, that's why cultural anthropologists can acquire more (information) about nation's culture, the way that they think 
and their ideology just by studying their language and analyze and interpret it better. Otherwise we can acquire information about nation's culture and the way that they thought just by analyzing their language and surveying its impact on the language. He believes that the realizations and conceptions that we have are based on language authority that we speak. So the people that speak differently understand the world differently. Actually language can reflect differences that known as culture (Gharai Moghadam, 2003). Language and culture have a straight connection and relation together, because language is an instrument for transmitting culture so no language can exist in the lack of culture. The person's ability of learning language is strongly based on their realizing level and their domination on culture. If someone has rich information in the field of language learning but neglect from cultural matter, this negligence cause awkward mistakes in learning language. The language cannot exist without culture (Hayati, 2011).

\section{3. 2. Language and Identity}

Language based on culture is one of the most important and history making and a tool for transmitting experiences, knowledge, human intelligence and a vase for saving thoughts of previous generation and ancestor's culture (Falk, 1994). Language is the most dominant instrument in the reciprocal action process of human learning (Batbi, 1995). In contemporary era, the language portion $n$ plural genesis of human identity was studied and assisted seriously in such a way that arouses different opinions. The most dominant property of language is to put out republication correlation and also one of the matters that makes human's personality (Bigdeli, 1997). Although there are some partial differences, all of theoreticians emphasize on the role, registration, declaration of plural experience and writing historical memories of nations, because language is not only a neutral instrument in human's relation but has cultural and political importance (Gidenz, 1995). Language as a solidarity power has a special effect on the bedder of cultural growth and genesis and come off local and national identity, but being succeed in learning a language is depend on creativity, cultural creativeness and yet fluidity, mobility, adaptability and coordination are its fundamental elements (Godarzi, 2005). Language moreover than is carrying the identity meaning burden by itself, act like transmission channel for other identity elements just by creation and transmitting apprehensible semantic system, as we often know about our ancestor's attempt for saving national identity, historical identity, other values, myths and cultural and social habits just through the language, so the human as a self-conscious and social creature transmit their thought to their addressee and other generations by using the basic function of the language (Berger, 1996).

\section{3. 3. Language and social communication}

In social and cultural studies, language is an instrument for social communication and relation, actually it's one of the most important needs of human societies that the members of society can communicate and cooperation inevitably, so that they can solve each other's needs in this way. Such a skill is "the most important property of humans..., language is the greatest and most complex achievement of humanity. Language is usable for both physical needs. It allows people to create culture, collect experience and transmit equal behavior from a generation to another". Language is one of common cultural elements of society and a kind of communicating symbol, actually absorption of cultural elements or other communicating symbols happen by language. Language is the most organic instrument that humans have and use for communicating in society, so it possible the expression of particular speech in society 
for humans; language is not visible but it has properties that is prior than that. Such a symbolic and social connection can conjunct human's present to their future and cause knowledge collection and transmission from past to present and from present to the future, and this collection is possible in both written and oral form of language (Ghanadan and Coworkers, 1996). The written and speech like forms of language can provide new facilities for cultural collection and prompt the cultural and social condition development (process) of a society. According to this "human's symbolic connection happen in three styles. First one is speech like language that includes vocal patterns with meaningful (structures). It simplifies the communication teaching. The second kind of communication style is written language that include recording speech picture, it teaches how to save cultural heritages. The third kind of physical (language) that is obtained from vulgar politesse that means communicating with hand, face or totally with physical cues. Action and social interaction function of language can be found in human communication that all the members of society transmit their social message just by some arbitrary symbols and cues call alphabetical script; According to the language structure and its quality, it acts like an instrument or social communication symbol, this role and effect can be checked with colloquial language (Koen, 2003).

\section{3. 4. Language and Society and Technological Changes}

People that live in society with rather stable language and totally they have a regular social behavior can normally transmit their passages, thoughts and feeling with common language. The social quality of language, links it with other phenomenons, processes and many other social-cultural factors and this correlation is so (deep) that some people describe language as a mirror that reflect events and any other social-cultural alteration in society. But totally, the language and society have a bilateral relation together. They are always in changing and alteration process but without same speed. Overall, social changes are so faster than language changes but generally they change permanently. Speech style of language is faster than its written mode so it's obvious that the changes in speech style are reflected so faster than written mode. Language as a social entity and organ needs stability to act in communication role beside it needs to change with social alteration and adapt with moment needs. Industrial developments and evolutions in a society are the most important events that have a widely effect on language. Daily extension of science, different industries, production of different earthen phenomenon and crops, thoughts and new attitudes in a society can alter the language words normally (Saboktekin and Khosrojeri).

\section{3. 5. Learning language and culture}

Language and culture are corresponsive together. One's ability in learning language is depending on him/her domination and realization level of culture. There is no language without society and people always use language for communicating, and their language has combination of cultural qualities by itself. Different social conditions devote different cultural backgrounds, the sight extent increscent of person's (in learning new language) can help them to open their mind and learn about other nation's culture, that is the main reason of learning a language, so for the sake of domination on a language, learner should know about "details in object language culture and aware about the differences between his/her (nation) with other nations". Many linguisticians believe that teaching a language is not only about linguistics knowledge but also teaching culture. Teaching a foreign language is normally teaching culture and its purpose is to increase communication ability of language learners for the sake of extending friendship and mutual understanding of different countries but is not this cultural 
extension, new Imperialism purpose that is to universalize by cultural extension or the matter that call it cultural invasion in recent years? Because imperialistic critics, Humi Bahabaha and Edward said that one of the new methods Hegemoni (superior Domination) in cultural domination include process that person think that the object language culture is superior than $\mathrm{him} / \mathrm{her}$ and so an alienability process happen that is a kind of cultural alienation (Hayati, 2011). Using the words like cultural record, cultural disability and cultural pluralism in linguistics, and in the field of teaching language, is notifying that learning new language process as a first language or second has a reciprocal effect on culture. Even sometimes said that teach new language encourages cultural pluralism. Cultural pluralism is used when a person or a group of people have more than one assortment of cultural believes, values, habits and a teaching program that extent pluralism is known as multicultural teaching that show the effect of language on culture. Samuel Huntrington, American best known theoretician, believes that culture is one of the main elements of language (Razavi, 2013). Language and culture are two essential categories, and in teaching process, learners were familiar with related culture and its various components. About language and culture relation, classic populationists believe that language and its structure are impacted by its cultural environment. They believe that humans have a flexible mental structure that can accept any kind of culture without attending the existed and genetic limitations. But nowadays, populationists and sociologists don't believe only in cultural absolute domination on language in these two categories, but this matter is emphasized that language is a communication instrument and culture determines the foundation of this communication. Culture determines who communicate with whom but also that's the culture that determines what they speak about and how this speaking should be done. Also culture determines that in what situation, content and form two persons should use (haji Rostamlu, 2006).

\section{4. Mutual Effect of Language and Culture}

Culture and language have mutual effect on each other. Culture influence language through the matters that may be important for the members of particular society and have marked name or named by national and public covering or even language names are very important for adaption of a culture, not only a name but may be several names in a culture for comprehending, felling and surveying the personal differences that speakers of a language saying. Language can also influence the culture so that language more than reflecting the cultural processes, it forms the processes. Language reflects the culture of a society because humans react against motions and persons that be important for them; but according to some masters of theory belief, that's the language that make culture flexible. Although it's not absolute, different language speech style cause different ways of thinking, because there aren't proven witnesses that show the concurrent development of both language and culture and also witnesses on social structural processes by language qualities, and this matter cause language alteration or borrowing some elements from speech assemblies. Overall, according to affection and impressibly, language terms reflect both material and immaterial categories of society culture and people use them depend on their cultural condition, and adapt themselves with culture and cultural language govern society. Although they differ in usage way but people use some words and terms in a culture that may be different in other cultures. So we should refer to this mutual effect between language and culture (Ardabili, 2012). 


\section{4. 1. Language and Cultural identity detection}

Language influence the cultural identity detection that this matter is cause by (unlimited creativeness of language and diversity of human language), the diversity of words in language structure is because of extension in speech language that is under the impact of historical and cultural totality of a society; and make language like basic and fundamental factor for reaching to the special purposes; for example we can refer to cultural identity detection by language. In this situation cultures influence by language, and so development ground, affection and cultural evolution of language happen based on these interchanges between cultures. Each culture effected in structure and words depend on its mutual cooperation by other cultures, so we can say that "one of the most important language evolution ways is cultural consultation, moreover, changes in other social institutions relation between themselves and the way that they behave, changes the human relation with nature. For example extension in social work division with science and technology cause an extension in the conception of language and this affection was so visible in recent eras... if a language of a nation change, its semantic system that includes conceptions, words and phrases structure will change too. As it was said before, one of the basis factors of changing during the history was the races and nations and their languages encounters and contacts (Geranpaye, 1998).

\section{DISCUSSION AND DEDUCTION}

In recent years, our society change in the field of moral and cultural values, that was often against believes and values that govern on society. These changes were so obvious and visible that understands its factors and reasons was quested by experts of cultural and social science and even general people. It's remarkable that cultural evolution was in any society and it appeared in a form of acculturation, cultural publication and cultural evolution or even cultural invasion and camisade (Foroogh and Torabi, 2009). One of the reasons of this evolution is changing in language, according to the traditional directors belief, original and pure language always belong to the old eras and any changes in its structure shows the chaos and disorderliness in that language and it ruins and collapses our ancestor's language. The main language changing reasons are because of the entrance of industrial and cultural phenomenons, political, economic and cultural relations arrival of those who educated abroad, geographical factors (having mutual border), taboos and military conflictions. Systematic evolution is a part of language identity and maybe a part of human's identity. But the main reason of entrance foreign terms that is one of the important factors of language changes is by improvement of technology in the world that producing scientific and technical instrument in such a high speed that is innumerable. As these instruments and tools enter other countries, they also enter their commercial names and known with these names. Sometimes in translation the scientific books, translators can't find suitable equivalents and synonymous because of the abundant numbers of the technical terms and lack of time, so they enter the original terms and use them in their translation. The entrance of foreign terms can cause these results, include:

A- Obsoleteness and forgetfulness of foretime person's language and cut relation with culture and custom. 
B- Disturbance the language relation between people; means understanding and realization that cause social amity by itself.

But unfortunately scientists and experts are usually notify those kind of factors that aren't basic and fundamental, and instead of notifying the role of knowledge and knowledge changes, they notify the knowledge distributor factor that is media, so we always move behind knowledge and technology changes. It means that we look for solution after it caused evolution (changes). We should attend to this note that future language belongs to those who producing knowledge and technology because a society that produce knowledge and technology, will also choose the name for that technology. So we should look for equivalent or borrow the original terms that in this second way, we cause language changes, followed by cultural invasions.

\section{CONCLUSION}

Language, Technology and Culture are changing permanently but the extension, alteration and changing speed of technology is faster than language based on this (faster than) culture. So for cultural impressing and preventing language killing, we should determine and produce technology or have a language generation depend on that technology.

\section{References}

[1] Ardabili L., The role of language as museum of cultural social thoughts of a society in the field of research, the congress of language and social science concepts, Tehran, the office of Iran sociology assembly (2012).

[2] Bateni M., Language correlation and social matters of modern linguistics, fourth edition, Tehran: Agah publication (1995).

[3] Bideli M., General international right, eleventh edition, Tehran: Gangdanesh Library (1997).

[4] Petergil T., Social linguistics, survey on language and society, Mohammad Tabatabai translation, Age publication, Tehran (1997).

[5] Falk J., Linguistics and language, Khosro Gholamalizade translation, Astan Ghods Razavi (1994).

[6] Gharai M., Amani A., Cultural anthropology, abjad, Tehran(2003).

[7] Geranpaye B., Culture and society, Sharif publication, first edition, Tehran(1998).

[8] Godarzi H., Sayings about language and identity, national studies institution, Iranian civilization (2005).

[9] Gidenz A., Sociology, Manuchehr Saburi Kashani translation, Tehran, Nai publication (1995).

[10] Goen B., Survey on sociology, Gholam Abbas Tavasoli - Reza Fazel translation, Samt publication, first edition, Tehran (2003). 
[11] Razavi A., Deliberation on culture adequacy, language and teaching language, Iran cultural researches catalog (2013).

[12] Sharbatian M., Deliberation on language role in the field of social science studies, language and social science concepts congress, Tehran, the office of Iran sociology assembly (2012).

[13] Hayati D., Seyedi A., Survey the communication between cultures in language teaching: problems and solutions, National Content Conserism (2011). 